\title{
The Communication Complexity of Private Value Single Item Auctions
}

Citation for published version (APA):

Grigorieva, E., Herings, P. J. J., Müller, R. J., \& Vermeulen, A. J. (2006). The Communication Complexity of Private Value Single Item Auctions. Operations Research Letters, 34, 491-498.

https://doi.org/10.1016/j.orl.2005.07.011

Document status and date:

Published: 01/01/2006

DOI:

10.1016/j.orl.2005.07.011

Document Version:

Publisher's PDF, also known as Version of record

Document license:

Taverne

Please check the document version of this publication:

- A submitted manuscript is the version of the article upon submission and before peer-review. There can be important differences between the submitted version and the official published version of record.

People interested in the research are advised to contact the author for the final version of the publication, or visit the DOI to the publisher's website.

- The final author version and the galley proof are versions of the publication after peer review.

- The final published version features the final layout of the paper including the volume, issue and page numbers.

Link to publication

\footnotetext{
General rights rights.

- You may freely distribute the URL identifying the publication in the public portal. please follow below link for the End User Agreement:

www.umlib.nl/taverne-license

Take down policy

If you believe that this document breaches copyright please contact us at:

repository@maastrichtuniversity.nl

providing details and we will investigate your claim.
}

Copyright and moral rights for the publications made accessible in the public portal are retained by the authors and/or other copyright owners and it is a condition of accessing publications that users recognise and abide by the legal requirements associated with these

- Users may download and print one copy of any publication from the public portal for the purpose of private study or research.

- You may not further distribute the material or use it for any profit-making activity or commercial gain

If the publication is distributed under the terms of Article $25 \mathrm{fa}$ of the Dutch Copyright Act, indicated by the "Taverne" license above, 


\title{
The communication complexity of private value single-item auctions
}

\author{
Elena Grigorieva $^{\mathrm{a}}$, P. Jean-Jacques Herings ${ }^{\mathrm{b}}$, Rudolf Müller ${ }^{\mathrm{a}, *}$, Dries Vermeulen $^{\mathrm{a}}$ \\ ${ }^{a}$ Department of Quantitative Economics, Universiteit Maastricht, P.O. Box 616, 6200 MD Maastricht, The Netherlands \\ ${ }^{\mathrm{b}}$ Department of Economics, Universiteit Maastricht, P.O. Box 616, 6200 MD Maastricht, The Netherlands
}

Received 14 March 2005; accepted 28 July 2005

Available online 21 November 2005

\begin{abstract}
This paper is concerned with information revelation in single-item auctions. We compute how much data needs to be transmitted in three strategically equivalent auctions-the Vickrey auction, the English auction and the recently proposed bisection auction-and show that in the truth-telling equilibrium the bisection auction is the best performer.

(C) 2005 Elsevier B.V. All rights reserved.
\end{abstract}

MSC: C72; D44

Keywords: Single-item auction; Communication complexity; Information revelation; Data transmission

\section{Introduction}

A classical challenge of auction design is to develop mechanisms that have an implementation in weakly dominant strategies resulting in an efficient allocation. Due to the Revelation Principle, focus has mainly been on direct revelation mechanisms. In the private value environment the challenge is considered to be solved since the Vickrey-Clarke-Groves direct mechanism implements the efficient allocation and is

\footnotetext{
* Corresponding author. Tel.: +31433883799; fax: +31433884874 .

E-mail addresses: e.grigorieva@ke.unimaas.nl (E. Grigorieva), p.herings@algec.unimaas.nl (P. Jean-Jacques Herings), r.muller@ke.unimaas.nl (R. Müller), d.vermeulen@ke.unimaas.nl (D. Vermeulen).
}

incentive-compatible $[1,5,10]$. However, by construction, implementation of a strategy in a direct mechanism requires elicitation of complete and exact preference information.

Recognition of the elicitation problem has prompted researchers to examine the trade-off between communication and allocation efficiency. For the case of combinatorial auctions, it has been recognized that full revelation of bidders' preferences may require a prohibitive amount of communication [7]. For the case of single-item auctions, the effect on allocative efficiency of a severe restriction of the amount of communication allowed is studied in Nisan and Blumrosen [6]. This paper considers the case where each bidder is only allowed to send a single $t$-bit message to the auctioneer, who must then allocate the object and determine the 
price according to the messages received. The authors determine the optimal auction and show that the loss of efficiency incurred relative to unconstrained auctions is mild. In Rothkopf and Harstad [8] similar questions are considered when bids are restricted to discrete levels in oral auctions. In particular, it is shown that for private values independently drawn from the uniform distribution the expected economic inefficiency is approximately proportional to the square of the increment.

In this paper, we are concerned with the issue of information (bidders' valuation) revelation and corresponding communication requirements of efficient incentive-compatible auctions for the case of selling a single indivisible object under private values. We will compare communication performance of three strategically equivalent auctions - the Vickrey auction, the English auction and the recently proposed bisection auction [4]. Under the Vickrey auction bidders are allowed to submit one single sealed bid. The bidder with the highest bid is declared to be the winner. He gets the object for a price equal to the second-highest bid that is made. In the English auction the auctioneer calls successively higher prices. Initially all bidders are active and, as the auctioneer raises the price, they decide when to drop out. No bidder who has dropped out can become active again. The number of active bidders as well as their bids are not publicly known at any time. The last bidder to remain is the winner and he pays the final ask price. The rules of the bisection auction will be presented later in the paper.

As Vickrey showed in [10], the Vickrey auction and the above variant of the English auction, are strategically equivalent. In [4] it is shown that the bisection auction is strategically equivalent to the Vickrey auction (and therefore, also to the English auction). Consequently, for these three auctions it holds that truthtelling is a weakly-dominant strategy, independent of the prior distribution of bidders' valuations, the number of bidders, or their risk attitude. Moreover, the resulting truth-telling equilibrium is efficient, meaning that the object gets assigned to the bidder who values it most. But the information about bidders' valuations that needs to be revealed to the auctioneer in order to decide on the allocation and the payment is different for these auctions. In the truth-telling equilibrium all valuations in the Vickrey auction and all but the highest valuation in the English auction are revealed to the auctioneer with a precision up to the very last digit. This is not necessarily a desirable feature of these auction formats. Bidders might be reluctant to truthfully reveal their full private value if there will be subsequent auctions or negotiations in which the information revealed can be used against them. Such considerations lead to an interest in auctions where bidders need not reveal their information entirely but only partially [2,9]. That is indeed what happens in the bisection auction. There only a bidder with the second highest valuation reveals his valuation, something that is inevitable in a Vickrey implementation [3]. It means that the bisection auction is economical in its demand for information. It elicits much less information about bidders' valuations than the Vickrey and English auctions but still enough to guarantee an efficient allocation.

The primal contribution of this paper is to analyze precisely the communication complexity associated with the revelation of bidders' valuations in these three auctions. Communication complexity is measured by the number of information bits that bidders should transmit during the auctions in the truth-telling equilibrium. By a bit, we mean the smallest unit of information used by a computer, either 0 or 1 . We find that in expectation the corresponding number in the bisection auction is far less than in the Vickrey and English auctions. In order to show this, we derive formulas for the expected number of information bits in these auctions with $n$ players whose valuations are integer numbers uniformly and independently drawn from the interval $\left[0,2^{R}\right.$ ) for some positive integer $R$. While we find that in the Vickrey auction $R n$ information bits and in the English auction at least $\frac{1}{3} n 2^{R}$ information bits are to be transmitted, it turns out that the bisection auction requires transmission of at most $2 n+R$ information bits.

\section{The bisection auction}

Suppose a single indivisible object is auctioned. Bidders' valuations are supposed to be integer, randomly drawn from a bounded interval-by default of the form $\left[0,2^{R}\right)$ for some positive integer $R$. The bisection auction has $R$ rounds. The price sequence starts at the middle of the initial interval with a price equal 
to $2^{R-1}$. (Instead of choosing the middle of the interval one may chose any integer inside the interval. In particular, in case of not uniformly distributed valuations one should choose the median in order to let the analysis of Section 3.1 go through.) Bidders report their demand at the current price by sealed bids. A yes-bid stands for the announcement to be willing to buy at the current price, a no-bid for the contrary. As a function of these bids, the auctioneer announces the price of the next round.

In case there are at least two players submitting a yes-bid, the price goes up to the middle of the upper half interval, i.e., the interval $\left[2^{R-1}, 2^{R}\right)$. The players that are allowed to participate actively in the next round are the ones that said yes and they are competing for the object in the price range $\left[2^{R-1}, 2^{R}\right)$. The other players drop out of the auction and no longer have any influence on the proceedings of the auction. In case there is at most one player saying yes, attention shifts to the lower half interval, i.e. the interval $\left[0,2^{R-1}\right)$ and the price goes down to the middle of this interval. Two different things can happen now. First, the easy case, if no-one has submitted a yes-bid. In that case, all active players remain active in the next round. In the other case there is a single player that submitted a yes-bid. This player now becomes the winner and he gets the object. Nevertheless the auction does not end, but enters a price-determination phase. The active players in the next round are the ones that were active in the previous round minus the winner. In order to keep active players motivated to participate in the auction they should not get to know that the object has already been assigned. Therefore, we assume that bidders are not able to observe bids of the others. The remaining active players are competing on the lower half interval $\left[0,2^{R-1}\right)$. The winner, although he is no longer considered to be active, is considered to say yes to all prices that are proposed beyond the moment he became the winner. After all, all these prices will be lower than the price he agreed to when he became the winner. Apart from this, the way it is decided whether the price should go up or down is not any different from the way this is decided in the winner-determination phase. In each round depending on submitted bids we subsequently restrict attention to either the lower half of the current interval, or to the upper half of the current interval.
Iterating this procedure will eventually yield a winner and a price. In the case when in no round precisely one player said yes, several players will still be active after $R$ rounds, and the object is assigned by a lottery to one of them. The price is uniquely determined because in each round the length of the current interval goes down by a factor of two. Since the initial interval is of length $2^{R}$, after $R$ rounds the resulting interval is of length 1 . And since it is a half-open interval, it contains exactly one integer. This integer is declared to be the price the winner of the auction has to pay for the object.

Example. This example illustrates how the bisection auction works. Suppose there are four bidders, A, B, $\mathrm{C}$, and $\mathrm{D}$, with the following integer private valuations from the interval $[0,16): 11,7,15,9$. To determine the winner and the price in this setting the bisection auction takes four rounds and starts with an ask price equal to 8. Suppose that each bidder chooses to respond truthfully and follows a straightforward strategy under which he says yes if an ask price is less than or equal to his valuation and no otherwise. Bidders are not informed about other bidders' choices. The bisection auction proceeds as follows.

\begin{tabular}{lrrlllll}
\hline Round & Price & $\begin{array}{r}\text { Lower } \\
\text { bound }\end{array}$ & $\begin{array}{l}\text { Upper } \\
\text { bound }\end{array}$ & $\begin{array}{l}\text { Bidder } \\
\text { A }\end{array}$ & $\begin{array}{l}\text { Bidder } \\
\text { B }\end{array}$ & $\begin{array}{l}\text { Bidder } \\
\text { C }\end{array}$ & $\begin{array}{l}\text { Bidder } \\
\text { D }\end{array}$ \\
\hline 1 & 8 & 0 & 16 & yes & no & yes & yes \\
2 & 12 & 8 & 16 & no & - & yes & no \\
3 & 10 & 8 & 12 & yes & - & (yes) & no \\
4 & 11 & 10 & 12 & yes & - & (yes) & - \\
\hline
\end{tabular}

Since three bidders submitted yes-bids in the first round, the price increases to the middle of the current price and the current upper bound. So the ask price of the second round is 12 . These three bidders remain active while bidder B drops out. Since there is only one yes-bid in the second round we have a winner and we enter what we call the price determination phase. From now on, the winner, bidder $\mathrm{C}$, is considered to say yes. Players A and D are still active. In the third round, there are two yes-bids so the price increases. Player D drops out. In the fourth round, the auction terminates. Taking into account bids made during the last round we compute the final lower and upper bounds. Since there were 2 yes-bids the upper bound remains to be 12 while the lower bound becomes 
11. The winner, bidder $\mathrm{C}$, takes the object and pays price 11 which is the smallest Walrasian price for the demand announced by the bidders that participated in this auction.

\section{Information revelation and data transmission in the auctions}

Because of the strategic equivalence with the Vickrey and English auctions shown in [4] we know that telling the truth in the bisection auction is an equilibrium in weakly dominant strategies. This allows us to compare for all three auctions the information bidders are required to reveal about their valuations in equilibrium. We will show that the bisection auction is more economical in its demand for information regarding valuations of the players than the Vickrey and the English auctions.

The tool we use to measure revelation of information is the amount of data that gets transmitted in equilibrium. Notice that the fact that we have truth telling in equilibrium indeed allows us to identify revelation of information with data transmission. We calculate and compare the expected number of information bits that are to be transmitted by players before the auctioneer can decide upon allocation and payment in the Vickrey, English and bisection auctions.

\subsection{Data transmission in the bisection auction}

In this subsection, we present an implementation of the bisection auction that requires players to transmit at most $2 n+R$ information bits.

The initial ask price is known to all players before the auction starts. During a round with an ask price $p_{r}$ each active player submits a bid 0 or 1 where 0 stands for the statement "My valuation is less than $p_{r}$ " and 1 stands for the contrary. So, during a round each active player sends a single bit of information to the auctioneer. We do not require inactive players to submit bids since the outcome of the auction does not depend on the actions of inactive players. After receiving bids from all active players the auctioneer counts the number of 1's and determines who remains active. To each player that participated in this round the auctioneer sends a message 0 or 1 where 0 stands for the announcement that the bidder is not active anymore and 1 stands for the contrary. A player that remains active uses the information about his own previous action to compute the price of the next round and submits his next bid. Recall that if he said yes in the previous round the price goes up, otherwise the price goes down.

We calculate the expected number of information bits to be transmitted from players to the auctioneer during the auction. We consider the setting where valuations of players are integer numbers drawn uniformly and independently from the interval $\left[0,2^{R}\right)$, for some integer $R$. We assume that each player follows his truth-telling strategy, i.e. he submits 1 to an ask price that is less than or equal to his true valuation and 0 otherwise. From this assumption it follows that in any round an active player submits 1 or 0 with equal probability. Indeed, any active player in current round $r$ has a valuation that is uniformly distributed in the interval between the current lower and the current upper bound. Together with the fact that a current ask price lies in the middle of this interval it gives us the desired probability of $\frac{1}{2}$.

Let $E_{\mathrm{BA}}(n, R)$ denote the expected number of information bits that will be transmitted from players in the auction of $n$ (remaining) active players and $R$ (remaining) rounds in the case where the winner is not found yet. Similarly, by $E_{\mathrm{BA}}^{*}(n, R)$ we denote the expected number of information bits that will be transmitted from players in the auction of $n$ (remaining) active players and $R$ (remaining) rounds in the case the winner has already been found.

First, we find a recursive formula for $E_{\mathrm{BA}}(n, R)$. During the first out of $R$ remaining rounds all active players submit bids, so that $n$ information bits are transmitted. Obviously, if only one round remains, then only $n$ bits are transmitted, so $E_{\mathrm{BA}}(n, 1)=n$. For $R>1$ several situations can occur. If during this round the winner happens to be found, then $n-1$ active players (everyone except the winner) and $R-1$ rounds remain. The probability of this event is equal to $n\left(\frac{1}{2}\right)^{n}$. If during this round the winner is not found then $k$ active players and $R-1$ rounds remain. Notice that if the winner is not found, the situation with only one active player in the next round cannot occur, so $2 \leqslant k \leqslant n$. For $k \neq n$ the probability that $k$ out of $n$ active players say yes is $P(k, n)=\left(\begin{array}{l}n \\ k\end{array}\right)\left(\frac{1}{2}\right)^{n}$. For $k=n$ this probability is $P(n, n)=2\left(\frac{1}{2}\right)^{n}$ (i.e. the probability 
that all $n$ players say yes plus the probability that all $n$ players say no). Thus, for $n>1$ and $R>1$ we find that

$$
\begin{aligned}
E_{\mathrm{BA}}(n, R)= & n+n\left(\frac{1}{2}\right)^{n} E_{\mathrm{BA}}^{*}(n-1, R-1) \\
& +\sum_{k=2}^{n} P(k, n) E_{\mathrm{BA}}(k, R-1) .
\end{aligned}
$$

Now we derive a recursive formula for $E_{\mathrm{BA}}^{*}(n, R)$. To do that we consider a situation where $n$ active players and $R$ rounds remain in the auction and during a previous round the winner was already found. During the first out of $R$ remaining rounds all active players submit bids, so that $n$ information bits are transmitted during this round. Again, if only one round remains, then only $n$ bits are transmitted, so $E_{\mathrm{BA}}^{*}(n, 1)=n$. If only one player happens to be active he remains active till the end of the auction and during the remaining $R$ rounds exactly $R$ bits will be submitted, so $E_{\mathrm{BA}}^{*}(1, R)=R$. For $n>1$ and $R>1$ several situations can occur. Depending on the bids in this round $k$ active players $(1 \leqslant k \leqslant n)$ and $R-1$ rounds remain. For $k \neq n$ the probability that $k$ out of $n$ players remain active is $P(k, n)=\left(\begin{array}{c}n \\ k\end{array}\right)\left(\frac{1}{2}\right)^{n}$. For $k=n$ this probability is $P(n, n)=2\left(\frac{1}{2}\right)^{n}$. Thus, for $n>1$ and $R>1$ we find that

$E_{\mathrm{BA}}^{*}(n, R)=n+\sum_{k=1}^{n} P(k, n) E_{\mathrm{BA}}^{*}(k, R-1)$.

We show now that both $E_{\mathrm{BA}}^{*}(n, R)$ and $E_{\mathrm{BA}}(n, R)$ have upper bounds that are linear in $n$ and $R$.

Lemma 3.1. For any $n \in \mathbb{N}$ and $R \in \mathbb{N}, E_{\mathrm{BA}}^{*}(n, R)$ $\leqslant 2 n+R-2$.

Proof. The proof is by induction on $R$. Our induction proposition is

$P(R): \quad$ for every $n \in \mathbb{N}$ :

$$
E_{\mathrm{BA}}^{*}(n, R) \leqslant 2 n+R-2 .
$$

The basis of induction, $P(1)$, is trivial since $E_{\mathrm{BA}}^{*}(n, 1)=n \leqslant 2 n+1-2=2 n-1$ is true for any $n \in \mathbb{N}$. Now suppose that the proposition $P(R-1)$ is true. Take $n \in \mathbb{N}$. If $n=1$ then we have $E_{\mathrm{BA}}^{*}(1, R)=R \leqslant 2+R-2=R$. If $n>1$ then, using the induction hypothesis,

$$
\begin{aligned}
E_{\mathrm{BA}}^{*}(n, R)= & +\sum_{k=1}^{n} P(k, n) E_{\mathrm{BA}}^{*}(k, R-1) \\
= & n+\sum_{k=1}^{n-1}\left(\begin{array}{l}
n \\
k
\end{array}\right)\left(\frac{1}{2}\right)^{n} E_{\mathrm{BA}}^{*}(k, R-1) \\
& +2\left(\frac{1}{2}\right)^{n} E_{\mathrm{BA}}^{*}(n, R-1) \\
\leqslant & +\sum_{k=1}^{n-1}\left(\begin{array}{l}
n \\
k
\end{array}\right)\left(\frac{1}{2}\right)^{n}(2 k+R-3) \\
& +2\left(\frac{1}{2}\right)^{n}(2 n+R-3) \\
= & +2 \sum_{k=0}^{n}\left(\begin{array}{l}
n \\
k
\end{array}\right)\left(\frac{1}{2}\right)^{n} k \\
& +2 n\left(\frac{1}{2}\right)^{n}+\sum_{k=0}^{n}\left(\begin{array}{l}
n \\
k
\end{array}\right)\left(\frac{1}{2}\right)^{n}(R-3) \\
= & 2 n+2 n\left(\frac{1}{2}\right)^{n}+R-3 .
\end{aligned}
$$

Since for any $n$ it holds that $2 n\left(\frac{1}{2}\right)^{n} \leqslant 1$ we have the desired inequality.

Theorem 3.2. For any integer $n \geqslant 2$ and $R \in \mathbb{N}$, $E_{\mathrm{BA}}(n, R) \leqslant 2 n+R$.

Proof. The proof is by induction on $R$. Our induction proposition is

$P(R)$ : for every integer $n \geqslant 2$ :

$$
E_{\mathrm{BA}}(n, R) \leqslant 2 n+R \text {. }
$$

The basis of induction, $P(1)$, is trivial since $E_{\mathrm{BA}}(n, 1)=n \leqslant 2 n+1$ is true for any integer $n \geqslant 2$. Now suppose that the proposition $P(R-1)$ is true. Take an integer $n \geqslant 2$. Using the induction hypothesis and the result of Lemma 3.1 we have

$$
\begin{aligned}
E_{\mathrm{BA}}(n, R)= & n+n\left(\frac{1}{2}\right)^{n} E_{\mathrm{BA}}^{*}(n-1, R-1) \\
& +\sum_{k=2}^{n} P(k, n) E_{\mathrm{BA}}(k, R-1)
\end{aligned}
$$




$$
\begin{aligned}
= & +n\left(\frac{1}{2}\right)^{n} E_{\mathrm{BA}}^{*}(n-1, R-1) \\
& +\sum_{k=2}^{n-1}\left(\begin{array}{l}
n \\
k
\end{array}\right)\left(\frac{1}{2}\right)^{n} E_{\mathrm{BA}}(k, R-1) \\
& +2\left(\frac{1}{2}\right)^{n} E_{\mathrm{BA}}(n, R-1) \\
\leqslant & +n\left(\frac{1}{2}\right)^{n}(2 n+R-5) \\
& +\sum_{k=2}^{n-1}\left(\begin{array}{l}
n \\
k
\end{array}\right)\left(\frac{1}{2}\right)^{n}(2 k+R-1) \\
& +2\left(\frac{1}{2}\right)^{n}(2 n+R-1) \\
= & +2 n^{2}\left(\frac{1}{2}\right)^{n}+n\left(\frac{1}{2}\right)^{n}(R-5) \\
= & +n+R+\left(\frac{1}{2}\right)^{n}\left(2 n^{2}-4 n\right)-1 . \\
& +2 \sum_{k=2}^{n-1}\left(\begin{array}{l}
n \\
k
\end{array}\right)\left(\frac{1}{2}\right)^{n} k+4 n\left(\frac{1}{2}\right)^{n} \\
& +2\left(\frac{1}{2}\right)^{n}(R-1) \\
& +\sum_{k=2}^{n-1}\left(\begin{array}{l}
n \\
k
\end{array}\right)\left(\frac{1}{2}\right)^{n}(R-1) \\
& +2 n^{2}\left(\frac{1}{2}\right)^{n}+n\left(\frac{1}{2}\right)^{n}(R-5) \\
& +R-1-n\left(\frac{1}{2}\right)^{n}(R-1) \\
& +R \\
& +R
\end{aligned}
$$

It is straightforward to check that $f(n)=\left(\frac{1}{2}\right)^{n}\left(2 n^{2}-\right.$ $4 n) \leqslant 1$ for any integer $n \geqslant 1$. Thus the desired inequality $E_{\mathrm{BA}}(n, R) \leqslant 2 n+R$ holds.

So we can conclude that during the bisection auction on average not more than $2 n+R$ bits are transmitted from players to the auctioneer. Concerning a lower bound, it is easy to see that during the bisection auction at least $n+R-1$ information bits are to be trans- mitted from players to the auctioneer. Indeed, during the first round all $n$ active players send a bit and there is at least one active player during the remaining $R-1$ rounds.

\subsection{Comparison with the English auction}

The English auction starts with an ask price equal to 1. From round to round the price increases by a unit increment as long as at least two players announce their willingness to pay. Let us assume that only a synchronization signal is submitted: the auctioneer communicates price increments to all active players by sending 1 , while he communicates the end of the auction by sending 0 . Players update their price based on this signal and send 1 to the auctioneer if they are willing to buy at this price and 0 otherwise.

As in the bisection auction, we calculate the expected number of information bits which are to be transmitted during the auction from players to the auctioneer. Suppose that valuations of players are integer numbers uniformly and independently drawn from the interval $[0, L)$ for some integer $L$. We assume that all players follow their truth-telling strategies. In the first round with an ask price equal to 1 the probability that a player says yes is equal to the probability that his valuation is not equal to 0 which is $(L-1) / L$. For any player $i$ who remains active in the next round it holds that $v_{i} \in[1, L)$. So, the probability of saying yes in the second round (i.e. the probability of having valuation not equal to 1 ) given that the player is active is equal to $(L-2) /(L-1)$. And so on.

With $n$ active players in a round there will be $2 \leqslant k \leqslant n$ active players in the next round. By $P(k, n, L)$ we denote the probability that exactly $k$ out of $n$ active players, whose valuations are random integer numbers from a half-open interval of length $L$, say yes. Thus,

$P(k, n, L)=\left(\begin{array}{l}n \\ k\end{array}\right)\left(\frac{L-1}{L}\right)^{k}\left(\frac{1}{L}\right)^{n-k}$.

Let $E_{\mathrm{EA}}(n, L)$ denote the expected number of information bits transmitted from players in the auction of $n$ active players whose valuations are random integer numbers from a half-open interval of length $L$. Notice that for $L=2, E_{\mathrm{EA}}(n, 2)=n$. For $L \geqslant 3$ and $n \geqslant 2$ 
we find that

$$
\begin{aligned}
E_{\mathrm{EA}}(n, L)= & n+\sum_{k=2}^{n} P(k, n, L) E_{\mathrm{EA}}(k, L-1) \\
= & n+\sum_{k=2}^{n}\left(\begin{array}{l}
n \\
k
\end{array}\right)\left(\frac{L-1}{L}\right)^{k}\left(\frac{1}{L}\right)^{n-k} \\
& \times E_{\mathrm{EA}}(k, L-1) .
\end{aligned}
$$

We will use this recurrent equation to show that the average number of bits $E_{\mathrm{EA}}(n, L)$ that will be transmitted from players to the auctioneer has a lower bound of $\frac{1}{3} \operatorname{Ln}$.

Theorem 3.3. For any integer $n \geqslant 2$ and $L \geqslant 2$, $E_{\mathrm{EA}}(n, L) \geqslant \frac{1}{3} L n$.

Proof. The proof is by induction on $L$. Our induction proposition is

$P(L)$ : for every integer $n \geqslant 2: \quad E_{\mathrm{EA}}(n, L) \geqslant \frac{1}{3} L n$.

The basis of induction, $P(2)$, is trivial since $E_{\mathrm{EA}}(n, 2)=n \geqslant \frac{1}{3} 2 n$ is true for any integer $n \geqslant 2$. Now suppose that the proposition $P(L-1)$ is true. Take an integer $n \geqslant 2$. Using the induction hypothesis we have

$$
\begin{aligned}
E_{\mathrm{EA}}(n, L) & n+\sum_{k=2}^{n}\left(\begin{array}{l}
n \\
k
\end{array}\right)\left(\frac{L-1}{L}\right)^{k}\left(\frac{1}{L}\right)^{n-k} E_{\mathrm{EA}}(k, L-1) \\
\geqslant & n+\sum_{k=2}^{n}\left(\begin{array}{l}
n \\
k
\end{array}\right)\left(\frac{L-1}{L}\right)^{k}\left(\frac{1}{L}\right)^{n-k} \frac{1}{3}(L-1) k \\
= & n+\frac{1}{3}(L-1) \\
& \times\left[\left(\frac{L-1}{L}\right) n-n\left(\frac{L-1}{L}\right)\left(\frac{1}{L}\right)^{n-1}\right] \\
= & \frac{1}{3} n L+n\left(\frac{2}{3}-\frac{1}{3}\left(\frac{L-1}{L}+\frac{(L-1)^{2}}{L^{n}}\right)\right) .
\end{aligned}
$$

Finally, observe that $(L-1) / L \leqslant 1$ and $(L-1)^{2} / L^{n} \leqslant 1$ for any $L$ and any $n \geqslant 2$.

To compare the communication performance of the bisection and English auctions we look at the same range of valuations for both auctions. So we take interval $\left[0,2^{R}\right)$ and compare $E_{\mathrm{BA}}(n, R)$ with $E_{\mathrm{EA}}\left(n, 2^{R}\right)$. For valuations uniformly and independently drawn from the interval $\left[0,2^{R}\right)$ the bisection auction requires from players in expectation transmission of at most $2 n+R$ information bits while the English auction requires transmission of at least $\frac{1}{3} 2^{R} n$ bits.

It can easily be checked that for any $R \geqslant 4$ and any $n$ the upper bound of the expected number of bits transmitted by players in the bisection auction is less than the corresponding lower bound in the English auction. Moreover, it can be shown that for all $n$ and $R$ it holds that $E_{\mathrm{BA}}(n, R) \leqslant E_{\mathrm{EA}}\left(n, 2^{R}\right)$. From the above bounds it is clear that the expected number of information bits required by the English auction is exponential in the total expected number of information bits required by the bisection auction. Thus we can conclude that the bisection auction requires from players in expectation communication of far less information bits than the English auction.

\subsection{Comparison with the Vickrey auction}

To compare the communication performance of the bisection and Vickrey auctions we look again at valuations uniformly and independently drawn from the interval $\left[0,2^{R}\right)$. Any valuation from this interval can be represented using a binary encoding of length $R$. Submission of a valuation expressed in this way consists of $R$ information bits. Since during the Vickrey auction all players submit their exact valuation, this auction of $n$ players requires communication of $R n$ bits.

It can easily be shown that for any $n$ and $R$ the expected number of bits $E_{\mathrm{BA}}(n, R)$ transmitted from players in the bisection auction is less than the number $R n$ of corresponding bits in the Vickrey auction. Thus, we can conclude that the bisection auction requires from players in expectation far less communication than the Vickrey auction.

\section{Acknowledgements}

Elena Grigorieva and P. Jean-Jacques Herings acknowledge support by the Dutch Science Foundation NWO. Rudolf Müller acknowledges support by the European Commission through funds for the International Institute of Infonomics. 


\section{References}

[1] E.H. Clarke, Multipart pricing of public goods, Public Choice 11 (1971) 17-33.

[2] R. Engelbrecht-Wiggans, C.M. Kahn, Protecting the winner: second-price versus oral auctions, Econ. Lett. 35 (3) (1991) $243-248$

[3] J. Green, J.-J. Laffont, Characterization of satisfactory mechanisms for the revelation of preferences for public goods, Econometrica 45 (1977) 427-438.

[4] E. Grigorieva, P.J.-J. Herings, R. Müller, D. Vermeulen, The private value single item bisection auction. Research Memoranda, Maastricht Research School of Economics of Technology and Organization, RM/02/035, 2002, to appear in Economic Theory.
[5] T. Groves, Incentives in teams, Econometrica 61 (1973) 617-631.

[6] N. Nisan, L. Blumrosen, Auctions with severely bounded communication, Proccedings of the 43th Annual Symposium on Foundations of Computer Science, 2002.

[7] N. Nisan, I. Segal, The communication requirements of efficient allocations and supporting prices, J. Econ. Theory, 2005, to appear.

[8] M.H. Rothkopf, R.M. Harstad, On the role of discrete bid levels in oral auctions, Eur. J. Oper. Res. 74 (1994) 572-581.

[9] M.H. Rothkopf, T.J. Tisberg, E.P. Kahn, Why are Vickrey auctions rare?, J. Political Econ. 98 (1990) 94-109.

[10] W. Vickrey, Counterspeculation auctions and competitive sealed tenders, J. Finance 16 (1961) 8-37. 